\title{
On the Distribution of the Plankton in the East China Sea and Yellow Sea- $\mathrm{III}^{*}$ Description on the male of the pelagic Copepoda, Temora stylifera and T.discaudata
}

\author{
Takuo CHIBA \\ (Shimonoseki College of Fisheries) \\ Introduction
}

Temora stylifera and $T$ discaudata are distributed in the Southern waters in Japan. The female of both species and the male of Temora discaudata have been reported by Mori. But the mature male of Temora stylifera is not yet distinct in Japan. While studying on the plankton in the China Sea and Yello WSea, the writer could find the male of $T$. stylifera. I want to report mainly on the male of Temora stylifera and describe about $T$. discaudata in more detail than Mori's description.

\section{Systematic}

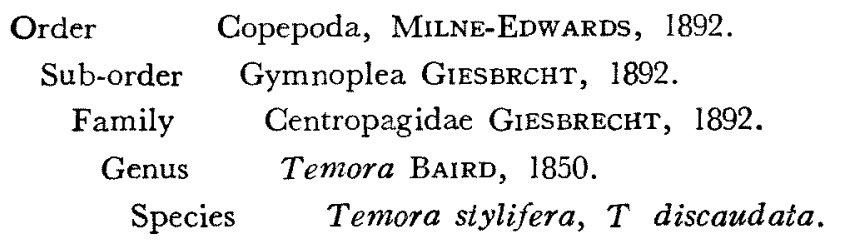

1. Temora stylifera (DANA) 1847.

Male : The head is separeted from the 1st thoracic segment. The lateral angles of the head are pointed. The length of the head is shorter than the width $(30: 47)$. The lateral angles of the last thoracic segment are also pointed. The anterior antenna consists of 24 segments and when reflexed it reaches to the end of the furca. The posterior division consists of 5 segments. The proportional length of the posterior divisicn is as followis :

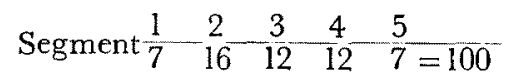

The furcal style is furnished with the hairs on the inner margin. The furcal setæis relatively short. The 5th pair of feet is asymmetrical. The right foot consists of 3

Received July 31, 1952. * Contribution from Shimonoseki College of Fisheries, No. 69 
segments. The 2nd segment has a thumb-like process on the inner margin. The terminal segment of that foot is lamelli-form and furnished with 4 marginal spines like that of Temora discaudata. The 2nd segment of the right foot is swelled. The 3rd segment of the right foot is not bent back against the outside of the foot as other foot, and extends straightly. The outer margin of the 3rd segment has 2 short spines. The exopodite of the 2 nd antenna is longer than the endopodite. The endopodite of the maxilliped with 1-segment, and slightly longer than the exopodite, which consists of 2 segments. The endopodite of the lst foot consists of 2 segments, and $1 / 2$ times as long as the exopodite, which consists of 3 segments. The endopodite from the 2nd to 4 th foot consists of 2 segments also, and $1 / 3$ times as long as the exopodite.

Length: $1.25 \sim 1.50 \mathrm{~mm}$.

Distribution: The mature female and the immature male have been recorded by Mori from following stations: $28^{\circ} 29^{\prime} 15^{\prime \prime}$ N. $128^{\circ} 38^{\prime} 5^{\prime \prime}$ E. , $29^{\circ} 26^{\prime} 30^{\prime \prime}$ N. $129^{\circ} 35^{\prime}$ E., $25^{\circ} 2945^{\prime \prime} \mathrm{N} .123^{\circ} 36^{\prime} 10^{\prime \prime} \mathrm{E}$, and $24^{\circ} 44^{\prime} 40^{\prime \prime} \mathrm{N} .120^{\circ} 1^{\prime} 30^{\prime \prime} \mathrm{E}$. I could catch the mature male at sea off Tanegashima, on April 12, 1952 and off Senzaki, on June 10, 1951.

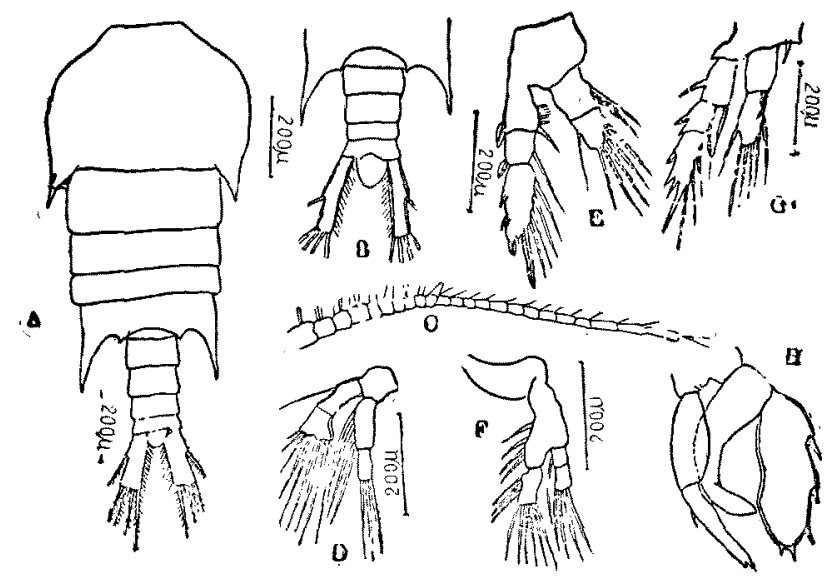

Fig. 1 The male of Temora stylifera

A. dorsal view. B. posterior division. C. 1st antenna, D. 2nd antenna.

E. 3rd foot F. mandible. G. 1st foot. H. 5th pair of feet.

2. Terrora discaudata Giesbrecht, 1889.

Male: The anterior division consists of 5 segments. The proportional length of the ariterior dision is as follows:

$$
\text { Segment } \begin{array}{ccccc}
1 & 2 & 3 & 4 & 6 \\
46 & 22 & 11 & 10 & 11=100
\end{array}
$$

The lateral arigles of the last thoracic segment are slightly asymmetrical and pointed. The left anterior antenna consists of 24 segments, and when reflexed, it 
reaches to the end of the last thoracic segment. The right antenna is modified into the grasping organ. The terminal section of that antenna is slightly swelled and has comb-like process on the outer margin. The proportional length of the anterior division and the posterior division is 63 to 40 . The furcal style is long and almost equal to the length of the abdomen, and swelled at the base and furnished with fine hairs. The proportional length of the posterior division is as follows:

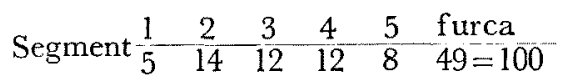

The endopodite from the 1 st to the 4 th pair of feet consists of 2 segments. The exopodite of these pairs of feet consists of 3 segments, and almost 3 times as long as the endopodite. The 5 th pair of feet is asymmetrical, and the left foot consists of 4 segments and the right foot consists of 3 segments. The thumb-like process of the 2nd segment of the left foot is swide, gradually curved, and extended to the last segment. The terminal segment of the left foot is lamelli-form and furnished with 4 marginal spines. The 3rd segment of the right foot is hook-like and sharply bent back against the outside of the foot.

Length : $1.62 \sim 2.15 \mathrm{~mm}$.

Distribution: This species commonly appears in warm currents. I have taken only the male of $\mathcal{T}$. discaudata at sea off Senzaki, on June 10, 1951.

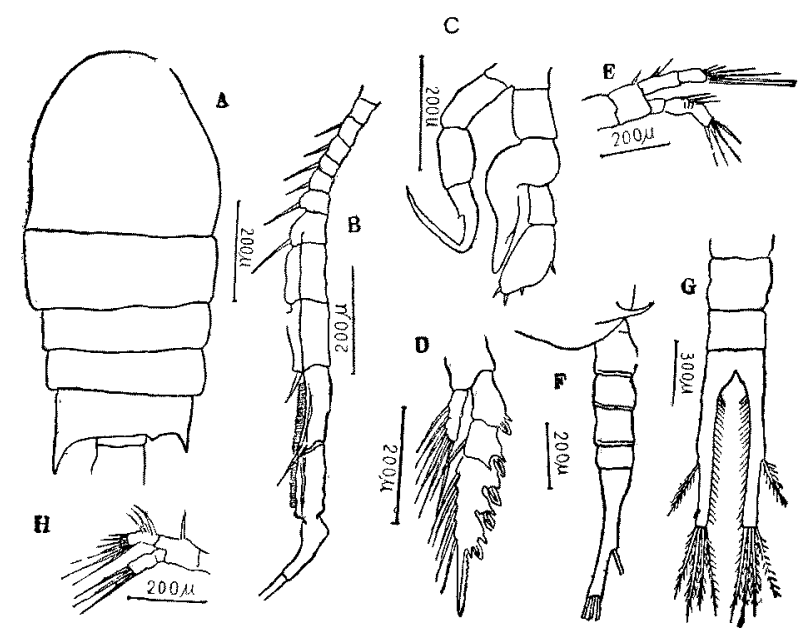

Fig. 2 The male of Temora discaudata

A. dorsal view. B. 1st antenna. C. 5 th pair of feet. D. 4th foot. E. 2nd antenna. F. posterior division, lateral view. G. furcal style. H. mandible.

\section{Literature}

1. Mori, T. The pelagic Copepoda from the neighbouring waters of Japan. 
(1937), p. 102.

2. Giesbrecht, W. u. Schmeil, O. Das Tierreich. 6, Copepoda. 1 Cymnoplea. (1898), Fp. 150-153. 